\title{
Antimicrobial Activity Evaluation on Silver Doped Hydroxyapatite/Polydimethylsiloxane Composite Layer
}

\author{
C. S. Ciobanu, ${ }^{1}$ A. Groza, ${ }^{2}$ S. L. Iconaru, ${ }^{1}$ C. L. Popa, ${ }^{1,3}$ P. Chapon, ${ }^{4}$ M. C. Chifiriuc, ${ }^{5,6}$ \\ R. Hristu, ${ }^{7}$ G. A. Stanciu, ${ }^{7}$ C. C. Negrila, ${ }^{1}$ R. V. Ghita, ${ }^{1}$ M. Ganciu, ${ }^{2}$ and D. Predoi ${ }^{1}$ \\ ${ }^{1}$ National Institute for Materials Physics, P.O. Box MG 07, 077125 Magurele, Romania \\ ${ }^{2}$ National Institute for Laser, Plasma and Radiation Physics, 409 Atomistilor Street, P.O. Box MG 36, 077125 Magurele, Romania \\ ${ }^{3}$ Faculty of Physics, University of Bucharest, 405 Atomistilor Street, P.O. Box MG1, 077125 Magurele, Romania \\ ${ }^{4}$ Horiba Jobin Yvon SAS, 16-18 Rue du Canal, 91165 Longjumeau Cedex, France \\ ${ }^{5}$ Microbiology Department, Faculty of Biology, University of Bucharest, 1-3 Portocalelor Lane, Sector 5, 77206 Bucharest, Romania \\ ${ }^{6}$ Earth, Environmental and Life Sciences Section, Research Institute of the University of Bucharest, 1-3 Portocalelor Lane, \\ Sector 5, 77206 Bucharest, Romania \\ ${ }^{7}$ Center for Microscopy-Microanalysis and Information Processing, University Politehnica of Bucharest, 313 Splaiul Independentei, \\ 060042 Bucharest, Romania
}

Correspondence should be addressed to D. Predoi; dpredoi@gmail.com

Received 14 April 2015; Accepted 26 May 2015

Academic Editor: Julietta V. Rau

Copyright (C) 2015 C. S. Ciobanu et al. This is an open access article distributed under the Creative Commons Attribution License, which permits unrestricted use, distribution, and reproduction in any medium, provided the original work is properly cited.

\begin{abstract}
The goal of this study was the preparation, physicochemical characterization, and microbiological evaluation of novel hydroxyapatite doped with silver/polydimethylsiloxane (Ag:HAp-PDMS) composite layers. In the first stage, the deposition of polydimethylsiloxane (PDMS) polymer layer on commercially pure Si disks has been produced in atmospheric pressure corona discharges. Finally, the new silver doped hydroxyapatite/polydimethylsiloxane composite layer has been obtained by the thermal evaporation technique. The Ag:HAp-PDMS composite layers were characterized by various techniques, such as Scanning Electron Microscopy (SEM), Glow Discharge Optical Emission Spectroscopy (GDOES), and X-ray photoelectron spectroscopy (XPS). The antimicrobial activity of the Ag:HAp-PDMS composite layer was assessed against Candida albicans ATCC 10231 (ATCC-American Type Culture Collection) by culture based and confirmed by SEM and Confocal Laser Scanning Microscopy (CLSM) methods. This is the first study reporting the antimicrobial effect of the Ag:HAp-PDMS composite layer, which proved to be active against Candida albicans biofilm embedded cells.
\end{abstract}

\section{Introduction}

One of the major problems encountered in modern medicine is to find new materials that can be integrated in the human body without being rejected by the host tissue. For this purpose, in the recent years, researchers worldwide have focused on the development of novel hybrid materials, by combining the polymer science and nanotechnology, for different biomedical applications, such as drug delivery [1-4] or biomimetic implants [1,5-9]. In order to be successfully integrated in the human body, the nanoengineered materials must have specific properties, like a good biocompatibility and biodegradability.
Hydroxyapatite (HAp), with the chemical formula $\mathrm{Ca}_{10}\left(\mathrm{PO}_{4}\right)_{6}(\mathrm{OH})_{2}$, belonging to the family of calcium phosphate ceramics is a good candidate for various biomedical applications. Due to its similarity to the mineral phase of human bone tissue and its outstanding properties, such as biocompatibility, bioactivity, osteoconductivity, porosity, and long degradation times [10-13], it has been widely used in orthopedic surgeries as coating material for hip and knee prosthesis or for bone reconstructions $[13,14]$. It has been also used in dentistry, as filler in dental prosthesis $[13,14]$. However, previous studies have shown that patients with implants coated with pure hydroxyapatite are more likely to develop microbial biofilm associated infections 
$[10,15]$. The biofilm associated infections are implicated in the etiology of $80 \%$ of human infections [8], being characterized by slow onset, middle intensity symptoms, chronic evolution, and resistance to antibiotic treatment [16], requiring complex multidrug treatment strategies [17]. One of the proposed solutions for this problem was to embed silver (Ag) nanoparticles in the structure of HAp.

It is well known that silver exhibits high antimicrobial activity against a large number of bacterial and fungal strains $[18,19]$. The silver nanoparticles attach to the bacterial cellular membrane causing modification of its permeability, thus disturbing the respiratory function $[18,20]$. Furthermore, in order to better improve the biological properties of hydroxyapatite, different polymers can be incorporated in its matrix. This way, both the properties of the host material and of the polymer can be preserved [21, 22]. One of the polymers used for this purpose is polydimethylsiloxane (PDMS), member of the group of polymeric organosilicon compounds. PDMS exhibits a series of very appealing properties, such as high thermal, ultraviolet (UV) and oxidative stability, very low glass transition temperature $\left(-123^{\circ} \mathrm{C}\right)$, low surface energy, hydrophobicity, high gas permeability, low permeability to water, low electrical conductivity, and physiological inertness $[21,23]$, thus making it a good candidate for improving the HAp mechanical properties. According to Mark [24], PDMS is part of a group of promising polymers with low surface energy for biological applications that have the capacity to effectively liberate the absorption of biofoulants. Moreover, recent studies conducted by Brady and Singer [25] have shown that the great freedom of free rotation silicon-oxygen back to bone obstructs the possibility of forming dipolar or hydrogen bonds with complementary functional groups of biofoulants. Lin et al. [26] in recent studies on synthesis and antimicrobial activities of polysiloxane-containing quaternary ammonium salts on bacteria and phytopathogenic fungi have shown that polysiloxanes are especially attractive as they proved particularly high static and dynamic flexibility in many solvents, high permeability, and special surface properties.

In particular, PDMS layers are extensively used in medical implants and biomedical devices becoming a preferred soft substrate for culturing different types of cells [27] due to their biocompatibility [28], nontoxicity toward many species of organisms, and biodegradability [29].

Therefore, it is expected that a hybrid material constituted of silver doped hydroxyapatite and PDMS will exhibit improved mechanical, biological, and antimicrobial properties, thus making it an excellent candidate for numerous biomedical applications.

In this study we reported for the first time the evaluation of antifungal biofilm activity on silver doped hydroxyapatite/polydimethylsiloxane (Ag:HAp-PDMS) composite layer. For these biological studies the silver doped hydroxyapatite/polydimethylsiloxane (Ag:HAp-PDMS) composite layer was formed after the deposition by thermal evaporation technique of three layers of Ag:HAp on a silicon substrate previously coated with a PDMS layer.

The Ag:HAp-PDMS composite layers were investigated by various techniques such as Scanning Electron Microscopy
(SEM), Glow Discharge Optical Emission Spectroscopy (GDOES), and X-ray photoelectron spectroscopy (XPS). The antimicrobial and antibiofilm activity of the Ag:HAp-PDMS composite layer were assessed against Candida albicans ATCC 10231 strains by culture based and confirmed by Confocal Laser Scanning Microscopy (CLSM) methods.

\section{Experimental Section}

\subsection{Sample Preparation}

2.1.1. Silver Doped Hydroxyapatite (Ag:HAp) Nanoparticles. In order to synthesize the silver doped hydroxyapatite (Ag:HAp) precursors of calcium nitrate $\left[\mathrm{Ca}\left(\mathrm{NO}_{3}\right)_{2} \cdot 4 \mathrm{H}_{2} \mathrm{O}\right.$, Aldrich, USA], ammonium hydrogen phosphate $\left(\left(\mathrm{NH}_{4}\right)_{2} \mathrm{HPO}_{4}\right.$, Wako Pure Chemical Industries Ltd.) and silver nitrate $\left(\mathrm{AgNO}_{3}\right.$, Alpha Aesare, Germany, 99.99\% purity) were used. Controlled amounts of ammonium hydrogen phosphate and silver nitrate were dissolved in ethanol. After adding distilled water, the solution was stirred vigorously for $24 \mathrm{~h}$ at $40^{\circ} \mathrm{C}$. In a separate container, a stoichiometric amount of calcium nitrate was dissolved in ethanol with vigorous stirring for $24 \mathrm{~h}$ at $40^{\circ} \mathrm{C}$. The Ca-containing solution was added slowly to the P-containing solution and then aged at room temperature for $72 \mathrm{~h}$ and further at $40^{\circ} \mathrm{C}$ for $24 \mathrm{~h}$. The composition ratios in the Ag: $\mathrm{HAp}\left(x_{\mathrm{Ag}}=0.5\right)$ sol were adjusted to have $[\mathrm{Ca}+\mathrm{Ag}] / \mathrm{P}$ as $1.67[30,31]$. The obtained Ag:HAp nanopowders were treated at $800^{\circ} \mathrm{C}$ for 6 hours.

\subsubsection{Deposition of PDMS Polymer Layer on Commercially} Pure Silicium (Si) Disks. The PDMS layers have been produced in atmospheric pressure corona discharge starting from liquid precursors of vinyl terminated polydimethylsiloxane. The details regarding the experimental set-up and the procedure of PDMS layer generation on metallic substrates was presented in $[32,33]$.

2.1.3. Deposition of Ag:HAp Nanoparticles on a Silicon Substrate Previously Coated with a PDMS Layer. The Ag:HAp $\left(x_{\mathrm{Ag}}=0.5\right)$ powder treated at a temperature of $800^{\circ} \mathrm{C}$ for 6 hours has been deposited by thermal evaporation technique as solid layer on a silicon substrate previously coated with a PDMS layer [34]. By this technique the Ag:HAp nanoparticles (source material) are evaporated in vacuum. The vapour particles travel directly to the substrate where they condense to a solid state. A HOCH VACUUM Dresden installation was used under environment conditions. The pressure in the deposition chamber was in the range of $8 \cdot 10^{-5}$ torr. The time range for a deposition cycle was around $120 \mathrm{~min}$. The substrate was maintained at room temperature and at ground electrical potential. The Ag:HAp powder evaporation temperature was $1100^{\circ} \mathrm{C}$. The tungsten boat temperature during the Ag:HAp powder evaporation is in the range of $1178-1205^{\circ} \mathrm{C}$. The distance between substrate and boat is $5 \mathrm{~cm}$.

The evaporation time measured during deposition is situated in the range $20 \mathrm{sec}$ for a maximum current intensity of $I=75 \mathrm{~A}$ and in the range of $15 \mathrm{sec}$ for a maximum current $I=80$ A. Taking into account the deposition characteristics 
such as the total amount of HAp totally deposited (in mg) and the substrate-boat distance, the calculated evaporation velocities were $v_{1}=0.167 \mathrm{mg} / \mathrm{s}$ or $v_{1} \sim 8.3 \mathrm{~nm} / \mathrm{s}$. The calculated thickness of the deposited Ag:HAp: 50\% layer, in the experimental conditions presented above, on a silicon substrate is about $480 \mathrm{~nm}$ [34]. In the presence of a PDMS layer on the substrate, the Ag:HAp evaporated particles diffuse into the PDMS layer during their travel to the substrate. When the Ag:HAp particles stop in the polymer layer they transfer their energy to the polymer. Thus, the local temperature increases and as the polymer is heated, the thermal condition of a new compound generation is assured. In the following sections, the obtained composite layer is investigated by different methods.

2.2. Characterization Methods. The morphology of the material was studied using a Quanta Inspect F Scanning Electron Microscope (SEM). The elemental local analysis of the coatings was performed using an energy dispersive spectroscope (EDS) detector from X-EDS (Energy Dispersive X-Ray Spectroscopy). Operating conditions were an accelerating voltage between 2 and $25 \mathrm{keV}$ (depending on the ratio signal/noise) with samples tilted at $25^{\circ} \mathrm{C}$ to get the optimal take off angle $\left(30^{\circ}\right)$ allowing a dead time around $20-30 \%$ and a collecting time of 90-120 s. The top surface analysis of the samples was studied by Glow Discharge Optical Emission Spectroscopy (GDOES) [35] using a GD Profiler 2 from Horiba/Jobin-Yvon. Glow Discharge Optical Emission Spectroscopy (GDOES) is an essential technique for direct analysis of bulk solids and for elemental surface analysis and depth profiling of thin films and industrial coatings [36]. The Xray photoelectron spectroscopy (XPS) measurements were performed using a VG ESCA 3 MK II XPS installation $(E k \alpha=$ $1486.7 \mathrm{eV}$ ). The vacuum analysis chamber pressure was $P \sim$ $3 \times 10^{-8}$ torr. The XPS recorded spectrum involved an energy window $w=20 \mathrm{eV}$ with the resolution $R=50 \mathrm{eV}$ with 256 recording channels. The XPS spectra were processed using Spectral Data Processor v 2.3 (SDP) software. After Shirley background subtraction, the deconvolution of the XPS curves was conducted by using a fitting procedure based on the summation of Gaussian functions. When irradiated with Xrays, electrons from the inner shells cause the apparition of several peaks with different shapes in the analyzed spectra. Due to the characteristics of the measurement device that can lead to distortions and the ionization process, the peaks can be considered a convolution of Lorentz and Gaussian functions. The Lorentz function is associated with the lifetime broadening described by the uncertainty principle which depicts the relation between the lifetime and the energy of the ejected electrons, whereas the Gaussian function is associated with the measurement process. Theoretically, in some cases, the complexity of the obtained spectra comprises asymmetries caused by photoelectric peaks. Moreover, when selecting a line shape for fitting experimental data, both the background shape and theoretical considerations must be taken into account. Since the energy of the radiation is not monochromatic and the electron analyzer resolution (pass energy) was $R=50 \mathrm{eV}$, the obtained spectra were processed using a Gauss function. Furthermore, it is well known that the Lorentz component increases for spectral lines with high binding energy. As a result, in this case, the Lorentz component is negligible. The hardness $(H)$ and Young's modulus $(Y)$ of the films were determined by nanoindentation experiments with a Berkovich indenter. The hardness and Young's modulus were extracted from nanoindentation measurements using approach similar to the Oliver and Pharr analysis method [37-39]. In order to avoid substrate interaction effects, the indentation depth is about $10 \%$ roughly of film thickness.

2.3. Antibiofilm Activity. The antibiofilm activity of the obtained composites carried out against Candida albicans (C. albicans) biofilms was quantified at 24 hours and 48 hours. In this purpose, C. albicans ATCC $10231(500 \mu \mathrm{L}$ of $0.5 \mathrm{McF}$ arland microbial suspension in sterile saline obtained from $24 \mathrm{~h}$ microbial cultures) was grown on the thin films immersed in $4 \mathrm{~mL}$ culture medium (liquid yeast peptone glucose, YPG). At intervals of 24 hours and 48 hours the thin films were removed from the culture medium, washed in sterile saline solution in order to remove the nonadherent yeast cells, introduced into sterile saline $(1 \mathrm{~mL})$, and then vortexed for suspending the microbial cells embedded in the biofilm formed on the thin films specimens. This whole procedure was repeated for thin films colonized with fungal biofilms for 48 hours. The density of the microbial suspension obtained by removing the formed biofilms at $24 \mathrm{~h}$ and $48 \mathrm{~h}$ was measured spectrophotometrically at $620 \mathrm{~nm}$. Duplicate thin films specimens were washed in saline solution, fixed in cold methanol, and prepared for CLSM examination [40]. In this purpose, the specimens were stained for 2 minutes with ethidium bromide and visualized in reflection and fluorescence modes by using a TCS SP confocal microscope, equipped with a 10X HCX PL FLUORITE objective, with a numerical aperture NA of 0.3. An Ar ion laser (488 nm) used to simultaneously acquire both reflection and fluorescence. A lateral resolution of about $600 \mathrm{~nm}$ was achieved [41].

\section{Results and Discussions}

The morphology and the features of the composite layers formed after the thermal evaporation of the Ag:HAp nanoparticles and their consecutive deposition on a PDMS layer/Si substrate were studied by Scanning Electron Microscopy (SEM). The Ag:HAp based coating covers entirely the Si substrate surface (with a diameter of $20 \mathrm{~mm}$ ) while the PDMS layer was deposited only on a circular area with a diameter of $10 \mathrm{~mm}$. An image of the interface zone between the Ag:HApPDMS composite layer and the Ag:HAp layer is presented in Figure 1(a). It can be observed that the polymer acts as a matrix for the Ag:HAp coating. Both the Ag:HApPDMS composite layer and the Ag:HAp layer are compact, homogeneous, and with no cracks. Two high resolution SEM images of the Ag:HAp-PDMS composite layer are presented in Figure 1(b).

In order to investigate the elements components and the chemical modification generated on PDMS and its effect on silver doped hydroxyapatite film formation on the surface 


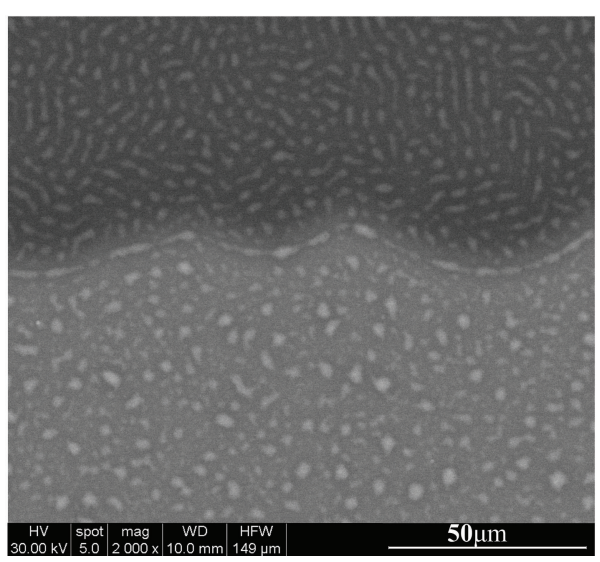

(a)

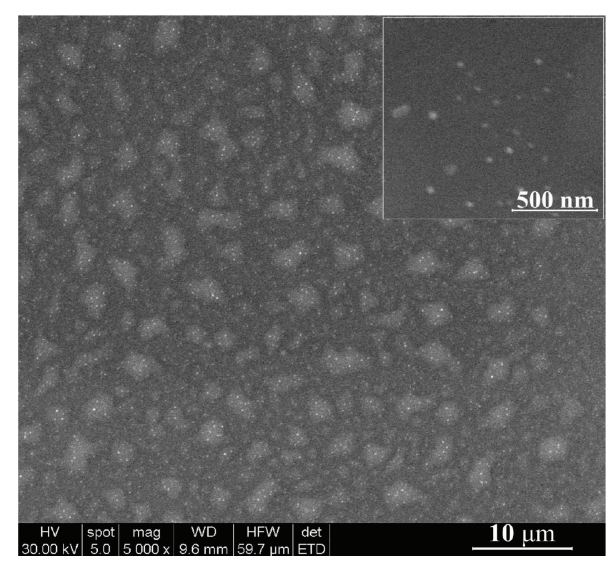

(b)

FIGURE 1: SEM image of (a) interface zone between the Ag:HAp-PDMS composite layer and the Ag:HAp layer; (b) Ag:HAp-PDMS composite layer with two different magnifications.

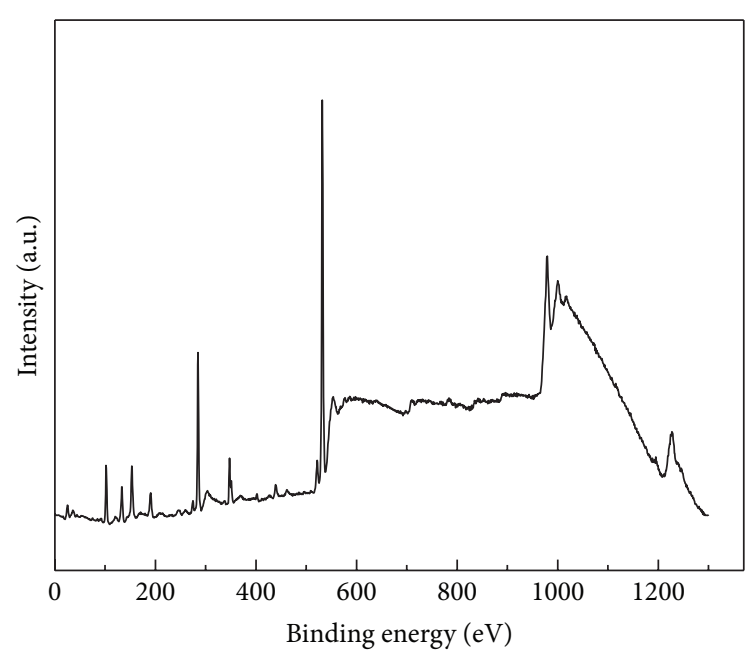

FIGURE 2: Survey spectra of Ag:HAp-PDMS composite layer.

of PDMS, X-ray photoelectron spectroscopy (XPS) measurements were performed. XPS high resolution spectra of the $\mathrm{C}$ 1s, Si 2p, O 1s, Ca 2p, P 2p, and Ag 3d regions were obtained. Figure 2 displays the survey spectra of Ag:HApPDMS composite layer. The measured binding energy $\left(E_{B}\right)$ scale was referenced to a $\mathrm{C} 1 \mathrm{~s}$ at the $E_{B}$ value of $284.8 \mathrm{eV}$ [42]. The accuracy for $E_{B}$ 's assignments is $\pm 0.2 \mathrm{eV}$. XPS spectral peaks for $\mathrm{C}$ 1s (Figure 3(a)) were deconvoluted into five Gaussian components attributed to $\mathrm{C} 1 \mathrm{~s}$ binding energies of the $\mathrm{C}-\mathrm{C}, \mathrm{C}-\mathrm{H}$, and $\mathrm{C}=\mathrm{O}$. In the opinion of Serra et al. [43] the peak positioned at $284.4 \mathrm{eV}$, corresponds to $\mathrm{C}-\mathrm{C}$ and $\mathrm{C}-$ $\mathrm{H}$ bonds. The peak at $284.7 \mathrm{eV}$ can be designated to $\mathrm{C}-\mathrm{C}$ group which is the primary chemical band of pure PDMS $[44,45]$. On the other hand, the peak at $285 \mathrm{eV}$ related to $\mathrm{C}-\mathrm{C}$ bond represents a part of adsorbed carbon on sample surface together with the $\mathrm{C}-\mathrm{C}$ bond in PDMS [46]. By Prieto et al. [47] the peak at $285.0 \mathrm{eV}$ is assigned to $\mathrm{C}-\mathrm{C}$ and C$\mathrm{H}$ hydrocarbon bonds. The peak at $286.1 \mathrm{eV}$ can be assigned to either $(\mathrm{O}-\mathrm{C})$ or carbonyl $(\mathrm{O}-\mathrm{C}=\mathrm{O})$ groups, respectively $[48,49]$. According to Prieto et al. [47] the peak at $286.1 \mathrm{eV}$ is due to $\mathrm{C}-\mathrm{OH}$ and $\mathrm{C}-\mathrm{O}$ bonds. The peak positioned at $283.4 \mathrm{eV}$ could correspond to C-metal bonds, showing a chemical interaction between $\mathrm{Ag}$ and contaminants from surface layer.

Figure 3(b) shows the high resolution XPS spectra of oxygen $\mathrm{O}$ 1s for Ag:HAp-PDMS composite layer. The $\mathrm{O} 1 \mathrm{~s}$ photoelectron peak was deconvoluted into four Gaussian components. According to previous studies presented by Zemlyanov et al. [50], the first component placed at $530.5 \mathrm{eV}$ can be assigned to the lattice oxygen (Ag-O-Si) of the Ag:HAp-PDMS thin film. According to the literature data on the oxygen and hydroxyl adsorption on $\mathrm{Ag}$ [51], the desorption temperature of the observed $\mathrm{O}$ 1s peaks allows attributing the peak at $531.1 \mathrm{eV}$ to surface $\mathrm{OH}\left(\mathrm{O}_{\text {ads }}^{\gamma-}\right)$ groups. This result is also in good agreement with previous studies of Kawabe et al. [52] believing that two oxygen species, that is, $\mathrm{O}^{-}$and $\mathrm{OH}^{-}$, may be included in the resolved peak at $531.1 \mathrm{eV}$. The peak at $532.3 \mathrm{eV}$ may be attributed to the oxygen linked to a phosphorous atom as in $\mathrm{PO}_{4}{ }^{3-}$ ions [53]. In conformity with previous XPS results reported by Jeon and Kang [54], Carroll et al. [55], and $\mathrm{Xu}$ and Khor [53], the small component at $534.0 \mathrm{eV}$ can be assigned to absorbed oxygen ( $\mathrm{Si}-\mathrm{O}$ ) and $\mathrm{O}-$ $\mathrm{C}-\mathrm{O}$ bonds. Figure 3(c) shows the high resolution XPS peak of Si 2 p core level. Si $2 p$ spectra can be separated into three Gaussian components.

The peak at $101.8 \mathrm{eV}$ can be attributed to Ag-O-Si linkages [56]. According to [53] and Mekki et al. [57], the binding energy of $\mathrm{SiO}_{4}{ }^{4-}$ was centred at $102.3 \mathrm{eV}$. The peak at $103.1 \mathrm{eV}$ was allocated to Si-O-Si linkages [58]. The Ca 2p spectrum of the Ag:HAp-PDMS composite layer exhibits a well-resolved doublet with a $\mathrm{Ca} 2 \mathrm{p}_{3 / 2}$ component and a $\mathrm{Ca}$ $2 \mathrm{p}_{1 / 2}$ component (Figure 3(d)).

The XPS spectral peaks for Ca $2 \mathrm{p}_{1 / 3}$ were decomposed into a two Gaussian components at around 350.6 and $351.2 \mathrm{eV}$ 


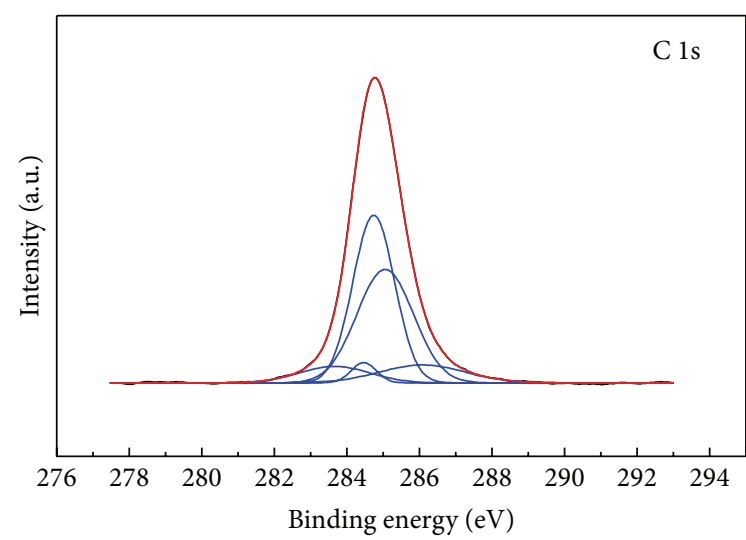

(a)

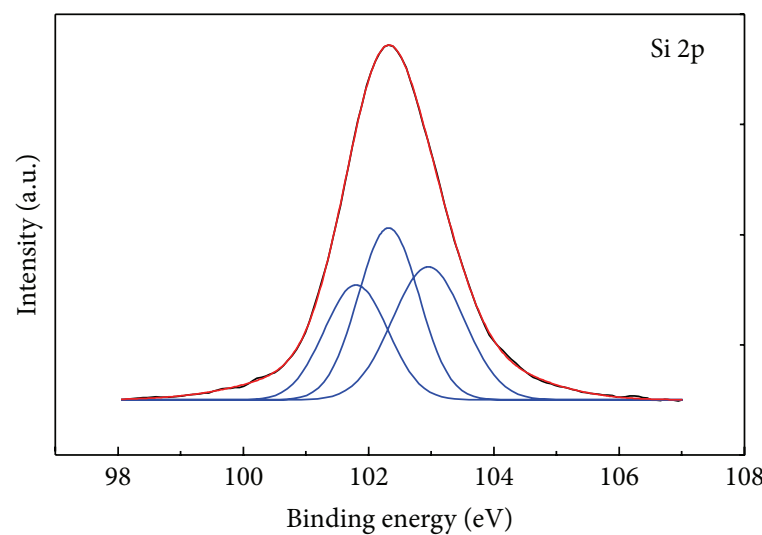

(c)

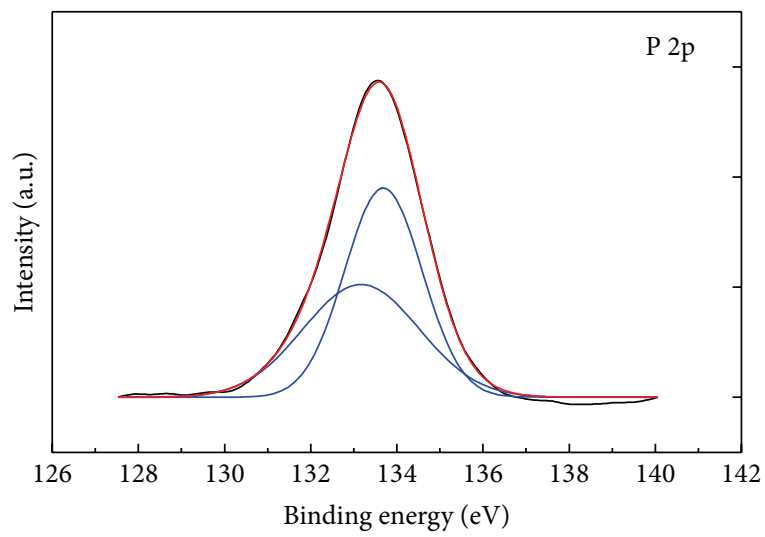

(e)

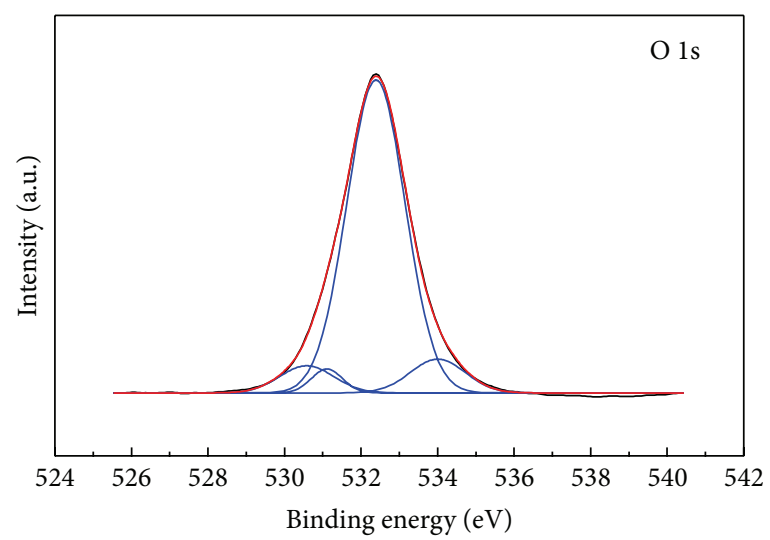

(b)

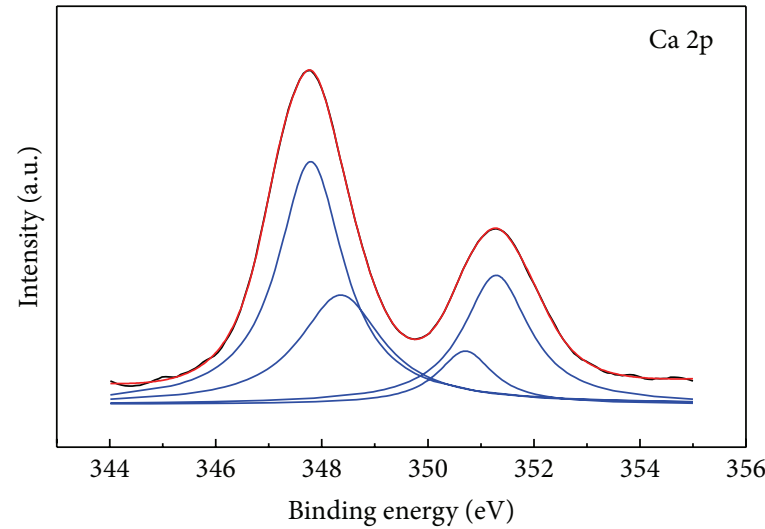

(d)

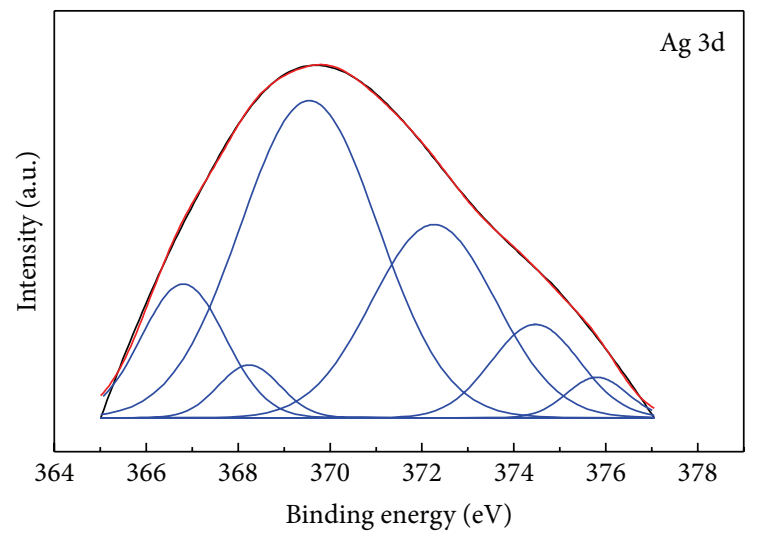

(f)

FIGURE 3: High resolution XPS spectra of C (1s) XPS peaks (a), O (1s) XPS peaks (b), Si (2p) XPS peaks (c), Ca (2p) XPS peaks (d), P (2p) XPS peaks (e), and Ag (3d) XPS peaks (f) of the Ag:HAp-PDMS composite layer.

[53]. The XPS spectral peaks for Ca $2 \mathrm{p}_{3 / 2}$ were decomposed into two Gaussian components. The first peak located at $347.8 \mathrm{eV}$ and the second peak located at about $348.3 \mathrm{eV}$ show that the calcium atoms are bonded with a phosphate group $\left(\mathrm{PO}_{4}{ }^{3-}\right)$ [53]. After the deconvolution data processing, the $\mathrm{P}$ $2 \mathrm{p}$ photoelectron line consists of two Gaussian components that were established at $133.1 \mathrm{eV}$ and $133.7 \mathrm{eV}$. These values are in the range of binding energies determined for hydroxyapatite $[59,60]$. The high resolution XPS spectra and curve-fitting results of phosphorous $\mathrm{P} 2 \mathrm{p}$ for Ag:HAp-PDMS composite layer are exhibited in Figure 3(e). Stoica et al. showed [61] that the P 2p photoelectron line consists of one 
single peak at $E_{B}$ position of $133.4 \mathrm{eV}$. The high resolution XPS spectra of the $\mathrm{Ag} 3 \mathrm{~d}$ region obtained from Ag:HApPDMS composite layer is presented in Figure 3(f). The Ag $3 d$ spectrum exhibits a broad doublet with an $\mathrm{Ag} 3 \mathrm{~d}_{5 / 2}$ and $\mathrm{Ag} 3 \mathrm{~d}_{3 / 2}$ component. The XPS spectral peaks for Ag $3 \mathrm{~d}$ were decomposed into six Gaussian components located at $366.7 \mathrm{eV}, 368.2 \mathrm{eV}, 369.5 \mathrm{eV}, 374.2 \mathrm{eV}, 374.4 \mathrm{eV}$, and 375.8 assigned to silver ions in $\mathrm{Ag}^{+}$and $\mathrm{Ag}^{2+}, \mathrm{Ag}_{2} \mathrm{O}\left(\mathrm{Ag}^{+}\right)$, and $\mathrm{Ag}-$ $\mathrm{O}$ and $\mathrm{Ag}-\mathrm{Ag}$, in good agreement with literature values [6265].

XPS results revealed that the silver from Ag:HAp-PDMS composite layer was assigned to $\mathrm{Ag}^{+}, \mathrm{Ag}^{2+}, \mathrm{Ag}_{2} \mathrm{O}\left(\mathrm{Ag}^{+}\right), \mathrm{Ag}-$ $\mathrm{O}$, and $\mathrm{Ag}-\mathrm{Ag}$ silver ions. These results showed that there was some kind of interaction between Ag from Ag:HAp and polydimethylsiloxane. On the other hand, the GDOES analysis has shown that during the deposition process there are some interactions of Ag:HAp particles with the polymer and thus the formation of a new composite material. Moreover, this study develops a novel and facile method to produce a new composite based on Ag (Ag:HAp-PDMS composite layer) which can be used for large-scale applications. The reproducibility, applications, and the price of the new products are not limited due to use of expensive precursors, such as tetraethoxysilane or due to the complicated synthesis route.

The GDOES spectra of the Ag:HAp-PDMS composite layer, presented in Figure 4, indicate that the Si, O, C, H (atoms specific to a PDMS layer) [66], P, Ca, Ag, and O (atoms specific to a Ag:HAp layer) [67] depth profile curves have similar temporal behaviour [34]. There is not any sharp increasing or decreasing in their depth profile curves as in the case of multilayer analysis [68]. Therefore, in correlation with the SEM and XPS analysis, the GD results indicate that during the thermal deposition process the Ag:HAp particles interact with the PDMS layer previously deposited on the silicon substrate determining the formation of a composite material.

The hypothesis of $\mathrm{Si}$ and $\mathrm{O}$ atoms redistribution in the bulk of the Ag:HAp-PDMS composite and their possible involvement in the $\mathrm{Si}-\mathrm{O}, \mathrm{Si}-\mathrm{O}-\mathrm{Ag}$, and $\mathrm{Si}-\mathrm{O}-\mathrm{P}$ bonds formation is also sustained by their depth profile curves in comparison with the $\mathrm{Si}$ and $\mathrm{O}$ depth profile curves observed in a PDMS layer [66] presented in Figure 4. The Si depth profile curve decreasing only after the Ca depth profile curve (and all the other elements) drop down can indicate not only the silicon involvement in the silicon oxides structures, $\mathrm{Si}-\mathrm{O}-$ $\mathrm{Ag}$, or Si-O-P bonds formation but also the incorporation of $\mathrm{SiO}_{4}{ }^{4-}$ ions in the hydroxyapatite doped with silver structure by the mechanism of $\mathrm{SiO}_{4}{ }^{4-} / \mathrm{PO}_{4}{ }^{3-}$ ions substitution as was suggested by the XPS studies presented above.

The hardness $(H)$ and Young's modulus $(Y)$ of our Ag:HAp layer on a silicon substrate are $2.7 \mathrm{GPa}$ and $98 \mathrm{GPa}$ and 2.6 GPa. For Ag:HAp-PDMS composite layer on a silicon substrate the $H$ and $Y$ values are $3.28 \mathrm{GPA}$ and $85 \mathrm{GPa}$, respectively. For Ag:HAp nanoparticles deposited on a silicon substrate previously coated with a PDMS layer (Ag:HApPDMS) the $Y$ modulus is lower than that for Ag:HAp layer while the $H$ modulus is greater than that for Ag:HAp layer. The values of $H$ and $Y$ moduli are influenced by the presence of PDMS. The values obtained for $H$ and $Y$ moduli are in agreement with existing literature for crystalline samples [69].

The fungal infections represent an emerging medical problem, particularly in immunocompromised patients [70]. Fungal pathogens can exhibit various mechanisms of resistance to common antifungals [71]. An important role in the evolution and treatment of fungal infections is attributed to microbial biofilms developed on natural tissues or artificial devices [72], according to NIH (National Institute of Health) [73].

The biofilm resistance is phenotypic and was also called tolerance [74]. One of the strategies employed to overcome this challenging problem is the design of novel biomaterials with improved resistance to microbial colonization. C. albicans represents the most prevalent fungal species involved in biofilm associated infections, either superficial or systemic ones [75-80]. Therefore, we have chosen to assess the antibiofilm activity of the novel composite layers against this fungal pathogen. The obtained composite layers have been proved to exhibit superior resistance to fungal colonization as compared with single materials used to obtain the composite (Figure 5). Concerning the dynamics of the fungal biofilm, it can be observed that the inhibition of the fungal biofilm development is gradually increasing from $24 \mathrm{~h}$ to $48 \mathrm{~h}$, as demonstrated by the lower absorbance values obtained for $48 \mathrm{~h}$ biofilms harvested from the Ag:HAp-PDMS composite layers (Figure 5(b)), as compared to those obtained for $24 \mathrm{~h}$ biofilms recovered from the same substratum (Figure 5(a)). Furthermore, on the rest of the tested materials, that is, SiPDMS layer and Si substrate, no significant differences have been noticed for the biofilms developed on these materials after $24 \mathrm{~h}$ and $48 \mathrm{~h}$.

These results could be explained by the fact that the silver incorporated in the HAp-PDMS matrix is gradually released and exhibits its antimicrobial effect on a prolonged period of time, preventing both the early phase of the fungal biofilm development in which yeast cells adhere to the substrate surface and undergo hyphal growth and the development of the mature biofilm, consisting of a mixture of yeast and hyphal elements forming a complex network encased in a self-produced extracellular material [81, 82].

The culture based results were confirmed by CLSM images revealing the fungal biofilms developed on different surfaces. Visualization of control biofilms revealed that the fungal biofilm stained in red by the ethidium bromide better developed on Si substrate and Si-PDMS layer, both at $24 \mathrm{~h}$ (Figures 6(a) and 6(c)) and $48 \mathrm{~h}$ (Figures 6(b) and 6(d)). In exchange, visualization of the biofilm structure developed on the Ag:HAp-PDMS composite layer revealed an important decrease in biofilm development (Figures 6(e) and 6(f)). This suggests the diffusion of Ag ions from the composite, exhibiting a prolonged antimicrobial and antibiofilm activity.

The growth of $C$. albicans biofilm on various substrates was also observed by Scanning Electron Microscope (SEM). Figure 7 presents photographs after $24 \mathrm{~h}$ and $48 \mathrm{~h}$ from microbial contamination with $C$. albicans. SEM observations have revealed different growth rates of the C. albicans biofilm on the silicon substrate, on the silicon substrate which was 


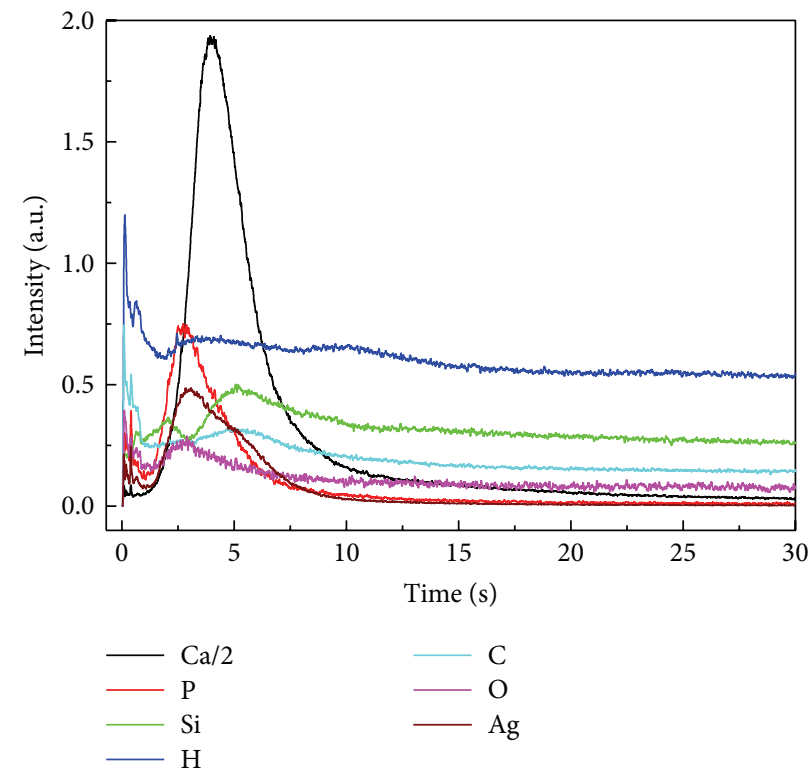

FIGURE 4: GDOES spectra of the Ag:HAp-PDMS composite layer formed on the Si substrate.

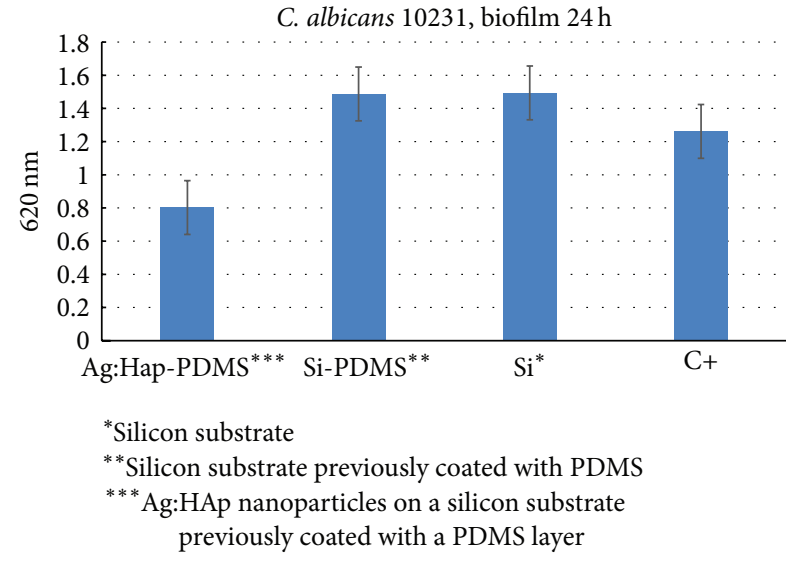

(a)

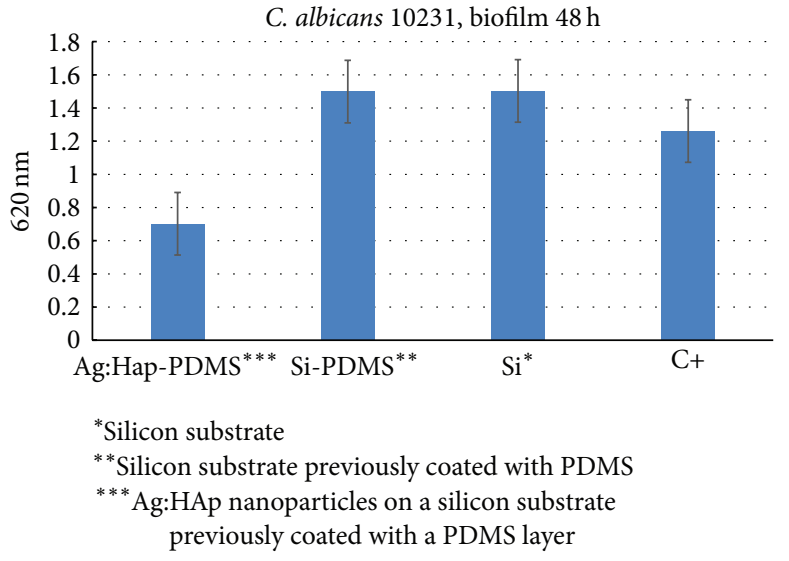

(b)

Figure 5: The graphic representation of the fungal biofilm development on different substrates, as revealed by the density of the microbial suspension recovered from the biofilms adhered on the tested specimens.

previously coated with PDMS and on the layer formed by deposition of Ag:HAp nanoparticles on a silicon substrate previously coated with a PDMS layer.

Also, it can be seen that the incubation time influenced the growth of $C$. albicans biofilm on different substrates. In the SEM images it is observed that the fungal biofilms have developed significantly on Si substrate (Figures $7(\mathrm{a})$ and $7(\mathrm{~b})$ ) and Si-PDMS layer (Figures 7(c) and 7(d)) both after $24 \mathrm{~h}$ and after 48 hours, matching the results obtained from CLMS images (Figure 6). A significant decrease of biofilm development was observed on the Ag:HAp-PDMS composite layer (Figures $7(\mathrm{e})$ and $7(\mathrm{f})$ ).

C. albicans is an important fungus responsible for systemic infections in humans. The increases of morbidity and mortality caused by C. albicans are very high and researchers worldwide are searching new alternative therapies and new drugs to reduce these infections. In conformity to Luo et al. [83] new prophylactic and therapeutic strategies are urgently needed to prevent fungal infection. According to recent studies conducted by Taglietti et al. [84] many Candida infections involve the formation of biofilms on implanted devices such as indwelling catheters or prosthetic heart valves. On the other hand, infections by C. albicans hospital acquired have become a cause of major health concerns. Silver nanoparticles represent a new generation of antimicrobial materials used as coatings. The silver nanoparticles have the ability to act locally, having a bactericidal effect. Nevertheless, the use of silver nanoparticles may pose a potential risk of cytotoxic effects on eukaryotic cells. To decrease a potential risk of cytotoxic effects of silver nanoparticles on eukaryotic cells, 


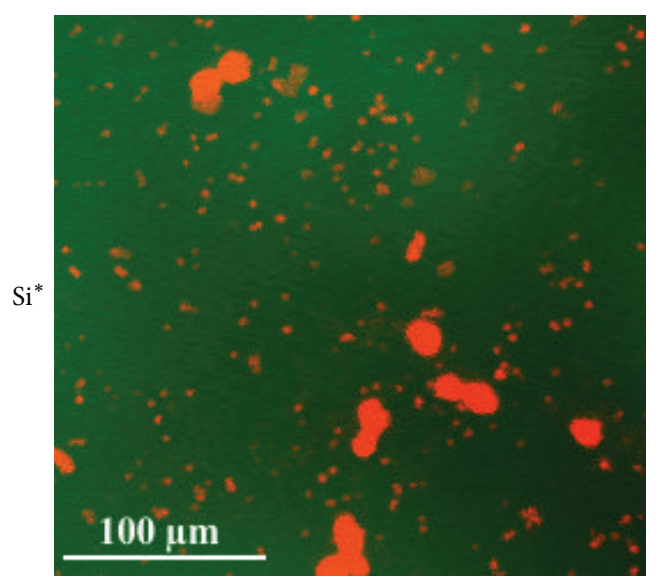

(a)

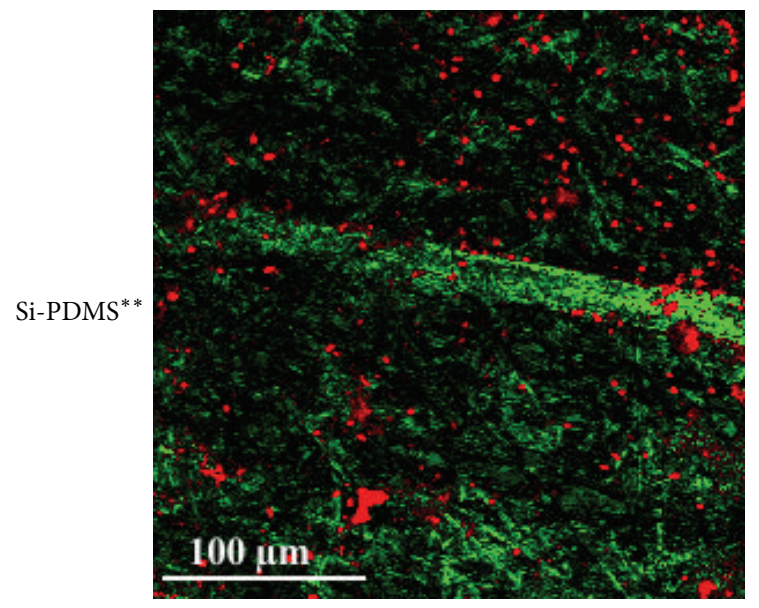

(c)

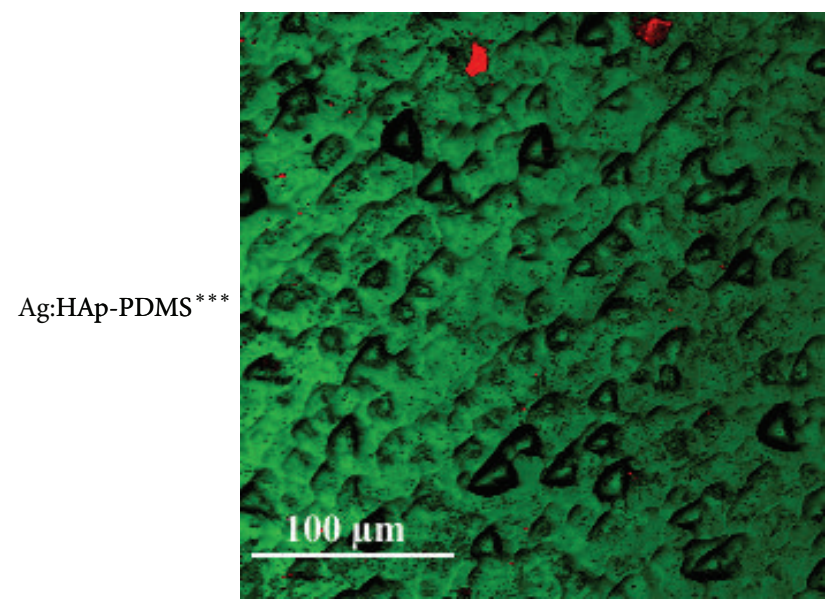

$24 \mathrm{~h}$

(e)

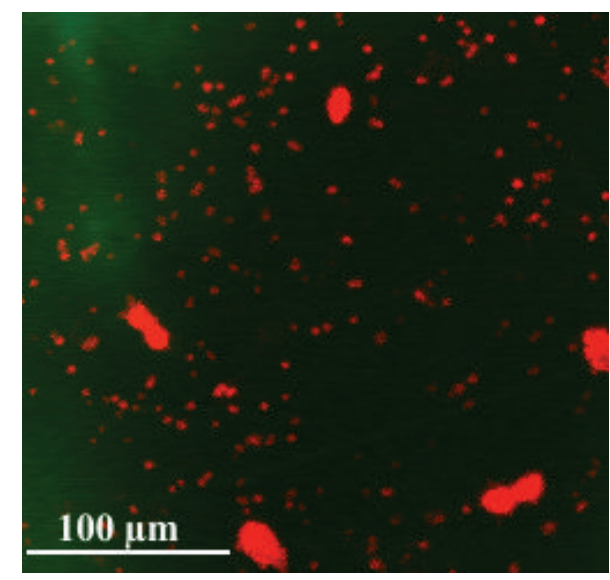

(b)

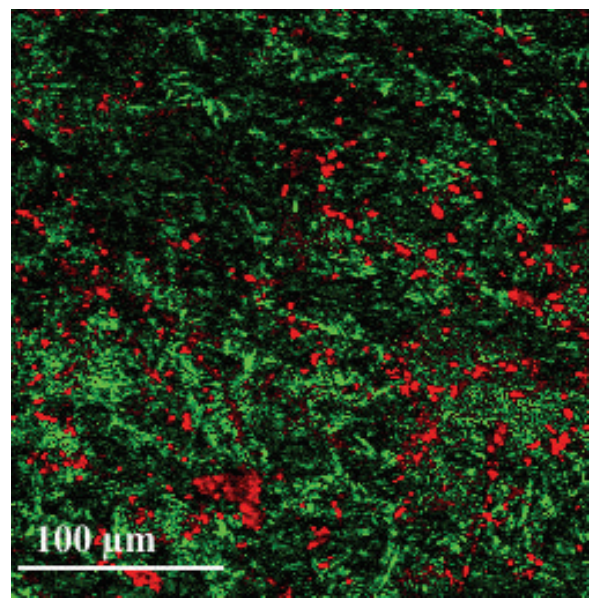

(d)

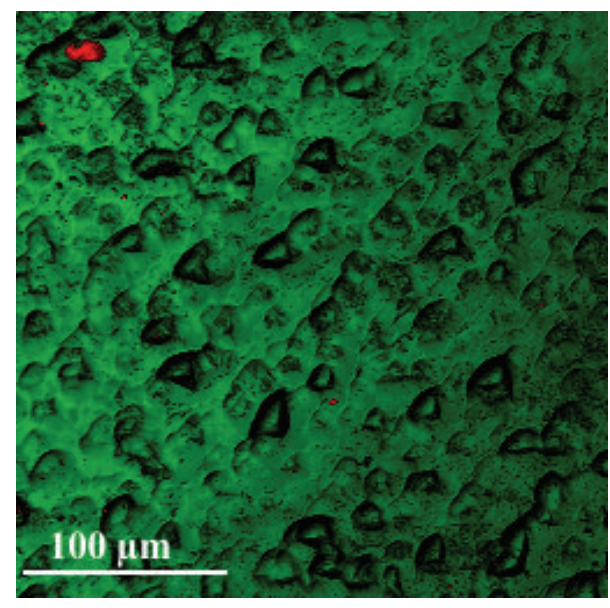

$48 \mathrm{~h}$

(f)

Figure 6: CLSM images of C. albicans biofilm stained with ethidium bromide developed on different substrata at $24 \mathrm{~h}$ and $48 \mathrm{~h}\left({ }^{*}\right.$ silicon substrate, ${ }^{* *}$ silicon substrate previously coated with PDMS, and ${ }^{* * *} \mathrm{Ag}:$ HAp nanoparticles on a silicon substrate previously coated with a PDMS layer). 


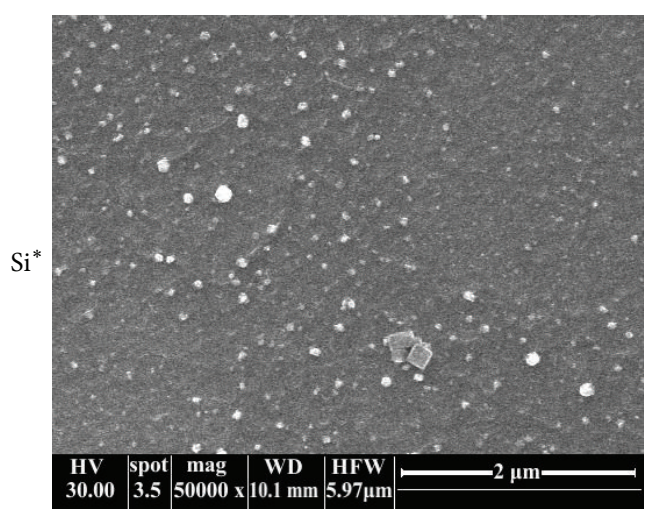

(a)

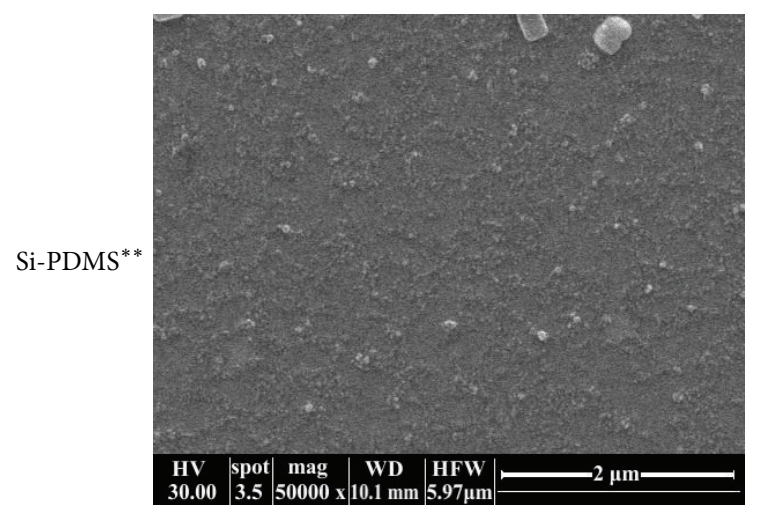

(c)

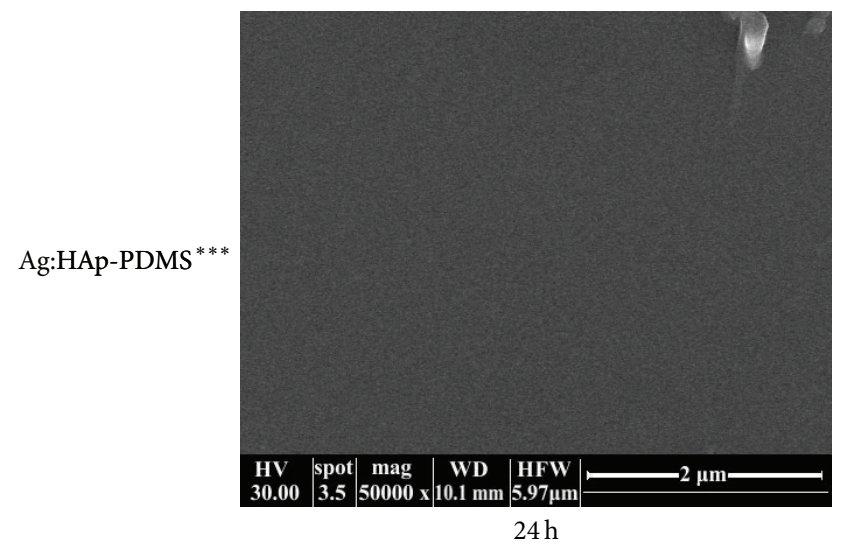

(e)

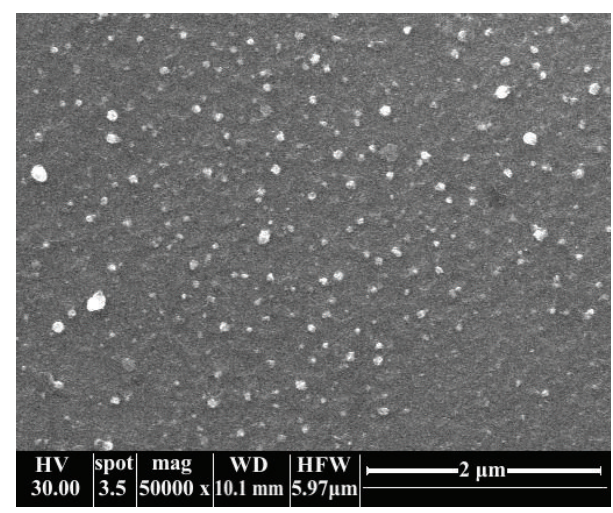

(b)

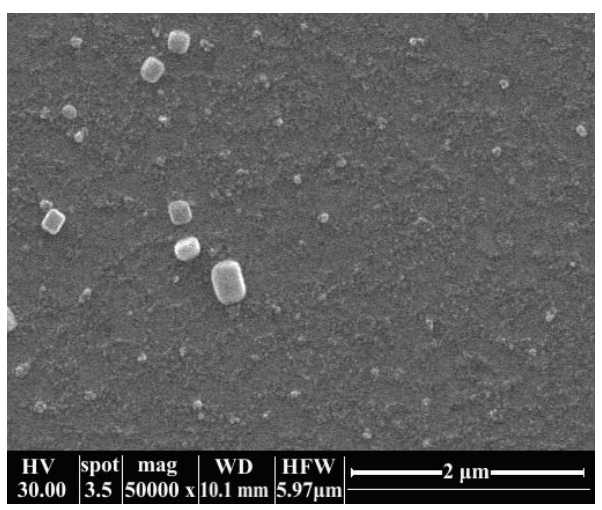

(d)

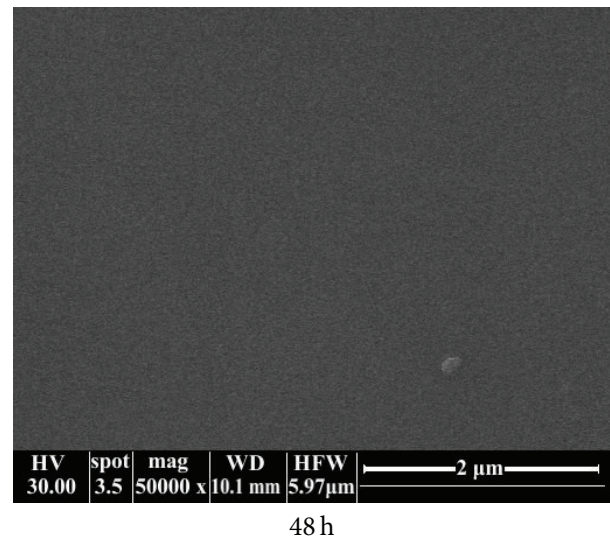

(f)

FIGURE 7: SEM photographs of C. albicans biofilm stained with ethidium bromide developed on different substrata at $24 \mathrm{~h}$ and $48 \mathrm{~h}\left({ }^{*}\right.$ silicon substrate, ${ }^{* *}$ silicon substrate previously coated with PDMS, and ${ }^{* * *} \mathrm{Ag}$ :HAp nanoparticles on a silicon substrate previously coated with a PDMS layer).

the composite materials endowed with bactericidal abilities have been achieved by adding the silver nanoparticles into various types of biomaterials.

Recent studies conducted by Ciobanu et al. $[85,86]$ on silver doped hydroxyapatite nanoparticles have demonstrated a good antimicrobial activity for all the studied concentration of the silver in the samples. Moreover, recent studies on thin solid films of silver doped hydroxyapatite prepared by sol-gel method [67] have also demonstrated a good antimicrobial activity against Escherichia coli and Staphylococcus aureus bacteria. It has thus been shown that the Ag:HAp thin films could be used to cover the surface of implantable medical devices. The results obtained in the studies presented in this paper demonstrate that, on the Si-PDMS layer and $\mathrm{Si}$ substrate, the microbial activity increases after $24 \mathrm{~h}$ and $48 \mathrm{~h}$ for biofilms developed on these materials. On the biofilm structure developed on the Ag:HAp-PDMS composite layer, the microbial activity decreases significantly for the surveyed 
time intervals. On the other hand, the CLMS technique used for the characterization of biofilm structure allowed us to obtain important information regarding the role of Ag ions in prolonged antimicrobial and antibiofilm activity.

In this context, novel hydroxyapatite doped with silver/polydimethylsiloxane (Ag:HAp-PDMS) composite layers is a primary target for new anti-infective strategy that could lead to a decrease in contamination with fungi and bacteria of medical devices by coating their surfaces. This study is part of the global research on the development of innovative biomaterials that possess anti-infective properties and technologies that allow the creation of bactericidal biomaterial surfaces $[87,88]$.

Fungal infections caused by C. albicans are determining factors for morbidity and mortality in both the immunocompetent and the immunocompromised critically ill patients (e.g., Human immunodeficiency virus infection/ acquired immunodeficiency syndrome (HIV/AIDS), cancer chemotherapy, and organ or bone marrow transplanted [89, 90]). According to [91] C. albicans efficiently adheres to polystyrene, polyvinylchloride, silicon, and polycarbonate, colonizing on their surfaces. Moreover, Shinde et al. [91] showed that Candida biofilms are highly resistant to drugs such as fluconazole. Furthermore, it was observed that C. albicans biofilm formation was dependent both on the microbial strain and on the substrate. Recent studies [91] on C. albicans SRTCC-06 isolated from the feces of a patient admitted to the tertiary care hospital for treatment of diarrhea and C. albicans SRTCC-11 isolated from a patient diagnosed with vaginitis have shown that the strain variation has a more pronounced effect on adhesion than the involved substrates. On the other hand, Shinde et al. [91] showed that the ability to adhere to prosthetic devices also depends on the properties of the cells and the substrate plays an important role in the biofilm formation of C. albicans. El-Azizi and Khardori [92], in their studies on "Factors influencing adherence of Candida spp. to host tissues and plastic surfaces," have shown that various properties including surface-free energy and roughness of the substrates may influence adhesion and biofilm development. Their results were confirmed by Raut et al. [93] in her studies on "Cell surface hydrophobicity and adhesion: a study on fifty clinical isolates of Candida albicans."

Considering that the fourth most common cause of nosocomial BSIs is the Candida strains [94], our data demonstrate that the substrates based on Ag:HAp-PDMS composite give a new perspective on the development of new prosthetic surfaces.

Our study was focused on creating a substrate that prevents the development of $C$. albicans biofilm thus creating an alternative solution to the issue of prosthesis-associated $C$. albicans infections. Results indicated an important decrease in biofilm development of C. albicans on Ag:HAp-PDMS composite layer and these composite layer based on Ag:HApPDMS may be used as potential prosthetic materials. Therefore we can say that the nature of the substrate can lead to a decrease of the C. albicans virulence.

\section{Conclusions}

Using XPS and GDOES spectral technique we have investigated the physicochemical processes that take place by the interaction of Ag:HAp particles with the PDMS layer. The XPS measurements showed that the physical procedure used for the generation of the Ag:HAp-PDMS composite layer allows the formation of $\mathrm{SiO}_{4}{ }^{4-}$ ions. The $\mathrm{SiO}_{4}{ }^{4-}$ ions can be incorporated into the Ag:HAp structures by substitution of $\mathrm{PO}_{4}{ }^{3-}$ ions from the structure of Ag:HAp. We suppose that after the condensation of the Ag:HAp particles on the substrate, due to the heating of the $\mathrm{SiO}_{2}$ network present into the polymer bulk, some $\mathrm{SiO}_{4}{ }^{4-}$ ions are generated. The crystalline structure of the Ag:HAp was also evidenced.

The GDOES depth profiling curves of the Ag:HAp-PDMS composite layer indicate that its composition is homogeneous which can be explained by the formation of the $\mathrm{Si}-\mathrm{O}-\mathrm{Ag}$, respectively, $\mathrm{Si}-\mathrm{O}-\mathrm{P}$ bonds and $\mathrm{Si}$ involvement in $\mathrm{Ag}: \mathrm{HAp}$ structure.

The development of C. albicans biofilm, both the initial adherence phase and the mature biofilm, was strongly inhibited by the Ag:HAp-PDMS composite layer, as shown by viable cell counts, CLSM, and SEM examination. Taking into account the important implications of C. albicans in human biofilm associated infection, the new composite materials could be of a great interest in the biomedical field, for the design of coatings that prevent or lag the fungal biofilm development.

\section{Conflict of Interests}

The authors declare that they have no competing interests.

\section{Authors' Contribution}

D. Predoi and A. Groza conceived the study. C. S. Ciobanu performed the synthesis of the powders. M. Ganciu performed the depositions of the PDMS thin films. R. V. Ghita performed the depositions of the Ag:HAp thin films. Characterization of materials was carried out by A. Groza, S. L. Iconaru, P. Chapon, M. C. Chifiriuc, R. Hristu, G. A. Stanciu, and C. C. Negrila. D. Predoi directed the study. D. Predoi, C. L. Popa, and A. Groza wrote the paper. All authors contributed to the interpretation of results and discussion and read, corrected, and approved the final paper.

\section{Acknowledgments}

This work was supported by the STAR Contract no. 53//20.11.2013 financed by the Romanian Space Agency.

\section{References}

[1] N. Roy and A. K. Bhowmick, "Tailor-made fibrous nanohydroxyapatite/polydimethylsiloxane composites: excavating the role of nanofiller aspect ratio, amorphicity, and noncovalent surface interaction," The Journal of Physical Chemistry C, vol. 116, no. 15, pp. 8763-8772, 2012. 
[2] P. Kallinteri, S. Higgins, G. A. Hutcheon, C. B. St. Pourçain, and M. C. Garnett, "Novel functionalized biodegradable polymers for nanoparticle drug delivery systems," Biomacromolecules, vol. 6, no. 4, pp. 1885-1894, 2005.

[3] J.-M. Pernaut and J. R. Reynolds, "Use of conducting electroactive polymers for drug delivery and sensing of bioactive molecules. A redox chemistry approach," Journal of Physical Chemistry B, vol. 104, no. 17, pp. 4080-4090, 2000.

[4] C.-S. Ha Jr. and J. A. Gardella, "Surface chemistry of biodegradable polymers for drug delivery systems," Chemical Reviews, vol. 105, no. 11, pp. 4205-4232, 2005.

[5] T. Desmet, R. Morent, N. De Geyter, C. Leys, E. Schacht, and P. Dubruel, "Nonthermal plasma technology as a versatile strategy for polymeric biomaterials surface modification: a review," Biomacromolecules, vol. 10, no. 9, pp. 2351-2378, 2009.

[6] S. J. Lee, C. Broda, A. Atala, and J. J. Yoo, "Engineered cartilage covered ear implants for auricular cartilage reconstruction," Biomacromolecules, vol. 12, no. 2, pp. 306-313, 2011.

[7] M. Schuler, G. R. Owen, D. Hamilton et al., "Engineered cartilage covered ear implants for auricular cartilage reconstruction," Biomaterials, vol. 27, no. 21, pp. 4003-4015, 2006.

[8] C. Saviuc, A. M. Grumezescu, A. Holban, C. M. Chifiriuc, D. Mihaiescu, and V. Lazar, "Hybrid nanostructurated material for biomedical applications," Biointerface Research in Applied Chemistry, vol. 1, pp. 64-71, 2011.

[9] C. Saviuc, A. M. Grumezescu, E. Oprea et al., "Antifungal activity of some vegetal extracts on Candida biofilms developed on inert substratum," Biointerface Research in Applied Chemistry, vol. 1, pp. 15-23, 2011.

[10] J. Qu, X. Lu, D. Li et al., "Silver/hydroxyapatite composite coatings on porous titanium surfaces by sol-gel method," Journal of Biomedical Materials Research Part B: Applied Biomaterials, vol. 97, no. 1, pp. 40-48, 2011.

[11] I.-S. Kim and P. N. Kumta, "Sol-gel synthesis and characterization of nanostructured hydroxyapatite powder," Materials Science and Engineering B, vol. 111, no. 2-3, pp. 232-236, 2004.

[12] D.-M. Liu, T. Troczynski, and W. J. Tseng, "Water-based sol-gel synthesis of hydroxyapatite: process development," Biomaterials, vol. 22, no. 13, pp. 1721-1730, 2001.

[13] S. Jadalannagari, K. Deshmukh, S. R. Ramanan, and M. Kowshik, "Antimicrobial activity of hemocompatible silver doped hydroxyapatite nanoparticles synthesized by modified sol-gel technique," Applied Nanoscience, vol. 4, no. 2, pp. 133-141, 2014.

[14] M. Díaz, F. Barba, M. Miranda, F. Guitián, R. Torrecillas, and J. S. Moya, "Synthesis and antimicrobial activity of a silverhydroxyapatite nanocomposite," Journal of Nanomaterials, vol. 2009, Article ID 498505, 6 pages, 2009.

[15] T. E. Rams, T. W. Roberts, D. Feik, A. K. Molzan, and J. Slots, "Clinical and microbiological findings on newly inserted hydroxyapatite-coated and pure titanium human dental implants," Clinical Oral Implants Research, vol. 2, no. 3, pp. 121-127, 1991.

[16] V. Lazar, "Quorum sensing in biofilms- - -how to destroy the bacterial citadels or their cohesion/power?" Anaerobe, vol. 17, no. 6, pp. 280-285, 2011.

[17] P. Y. Chung and Y. S. Toh, "Anti-biofilm agents: recent breakthrough against multi-drug resistant Staphylococcus aureus," Pathogens and Disease, vol. 70, no. 3, pp. 231-239, 2014.

[18] V. Jankauskaite, B. Abzalbekuly, A. Lisauskaite et al., "Silicone rubber and microcrystalline cellulose composites with antimicrobial properties," Materials Science, vol. 20, no. 1, pp. 42-49, 2014.
[19] H. Cao and X. Liu, "Silver nanoparticles-modified films versus biomedical device-associated infections," Wiley Interdisciplinary Reviews: Nanomedicine and Nanobiotechnology, vol. 2, no. 6, pp. 670-684, 2010.

[20] G. Thirumurugan and M. D. Dhanaraju, "Silver nanoparticles: real antibacterial bullets," in Antimicrobial Agents, V. Bobbarala, Ed., chapter 20, pp. 407-422, InTech, Rijeka, Croatia, 2012.

[21] O. Bareiro and L. A. Santos, "Tetraethylorthosilicate (TEOS) applied in the surface modification of hydroxyapatite to develop polydimethylsiloxane/hydroxyapatite composites," Colloids and Surfaces B: Biointerfaces, vol. 115, pp. 400-405, 2014.

[22] L. L. Hench, "Bioceramics," Journal of the American Ceramic Society, vol. 81, no. 7, pp. 1705-1728, 1998.

[23] W. Noll, Chemistry and Technology of Silicones, Academic Press, New York, NY, USA, 1978.

[24] J. E. Mark, "Some interesting things about polysiloxanes," Accounts of Chemical Research, vol. 37, no. 12, pp. 946-953, 2004.

[25] R. F. Brady Jr. and I. L. Singer, "Mechanical factors favoring release from fouling release coatings," Biofouling, vol. 15, no. 1-3, pp. 73-81, 2000.

[26] Y. Lin, Q. Liu, L. Cheng, Y. Lei, and A. Zhang, "Synthesis and antimicrobial activities of polysiloxane-containing quaternary ammonium salts on bacteria and phytopathogenic fungi," Reactive and Functional Polymers, vol. 85, pp. 36-44, 2014.

[27] J. N. Lee, X. Jiang, D. Ryan, and G. M. Whitesides, "Compatibility of mammalian cells on surfaces of poly(dimethylsiloxane)," Langmuir, vol. 20, no. 26, pp. 11684-11691, 2004.

[28] S. L. Peterson, A. McDonald, P. L. Gourley, and D. Y. Sasaki, "Poly(dimethylsiloxane) thin films as biocompatible coatings for microfluidic devices: cell culture and flow studies with glial cells," Journal of Biomedical Materials Research Part A, vol. 72, no. 1, pp. 10-18, 2005.

[29] L. Ceseracciu, J. A. Heredia-Guerrero, S. Dante, A. Athanassiou, and I. S. Bayer, "Robust and biodegradable elastomers based on corn starch and polydimethylsiloxane (PDMS)," ACS Applied Materials \& Interfaces, vol. 7, no. 6, pp. 3742-3753, 2015.

[30] C. S. Ciobanu, F. Massuyeau, L. V. Constantin, and D. Predoi, "Structural and physical properties of antibacterial Ag-doped nano-hydroxyapatite synthesized at $100^{\circ} \mathrm{C}$," Nanoscale Research Letters, vol. 6, article 613, pp. 1-8, 2011.

[31] C. S. Ciobanu, F. Massuyeau, E. Andronescu, M. S. Stan, A. Dinischiotu, and D. Predoi, "Biocompatibility study of europium doped crystalline hydroxyapatite bioceramics," Digest Journal of Nanomaterials and Biostructures, vol. 6, no. 4, pp. 1639-1647, 2011.

[32] A. Groza, A. Surmeian, M. Ganciu-Petcu, and I. I. Popescu, "Infrared spectral investigation of the linseed oil polymerization in a corona discharge in air at atmospheric pressure," Europhysics Letters, vol. 68, no. 5, pp. 652-657, 2004.

[33] A. Groza, A. Surmeian, C. Diplasu et al., "Physico-chemical processes occurring during polymerization of liquid polydimethylsiloxane films on metal substrates under atmospheric pressure air corona discharges," Surface and Coatings Technology, vol. 212, pp. 145-151, 2012.

[34] C. L. Popa, A. Groza, P. Chapon et al., "Physicochemical analysis of the polydimethylsiloxane interlayer influence on a hydroxyapatite doped with silver coating," Journal of Nanomaterials, vol. 2015, Article ID 250617, 10 pages, 2015.

[35] M. Wilke, G. Teichert, R. Gemma et al., "Glow discharge optical emission spectroscopy for accurate and well resolved analysis of coatings and thin films," Thin Solid Films, vol. 520, no. 5, pp. 1660-1667, 2011. 
[36] T. Nelis and R. Payling, Glow Discharge Optical Emission Spectroscopy: A Practical Guide, Royal Society of Chemistry, London, UK, 2003.

[37] W. C. Oliver and G. M. Pharr, "Improved technique for determining hardness and elastic-modulus using load and displacement sensing indentation experiments," Journal of Materials Research, vol. 7, no. 6, pp. 1564-1583, 1992.

[38] W. C. Oliver and G. M. Pharr, "Measurement of thin film mechanical properties using nanoindentation," MRS Bulletin, vol. 17, no. 7, pp. 28-33, 1992.

[39] G. M. Pharr, W. C. Oliver, and F. R. Brotzen, "On the generality of the relationship among contact stiffness, contact area, and elastic modulus during indentation," Journal of Materials Research, vol. 7, no. 3, pp. 613-617, 1992.

[40] C. M. Chifiriuc, V. Grumezescu, A. M. Grumezescu, C. Saviuc, V. Lazăr, and E. Andronescu, "Hybrid magnetite nanoparticles/Rosmarinus officinalis essential oil nanobiosystem with antibiofilm activity," Nanoscale Research Letters, vol. 7, article 209, 2012.

[41] C. Saviuc, A. M. Grumezescu, M. C. Chifiriuc et al., "In vitro methods for the study of microbial biofilms," Biointerface Research in Applied Chemistry, vol. 1, pp. 31-40, 2011.

[42] D. A. López, S. N. Simison, and S. R. De Sánchez, "The influence of steel microstructure on $\mathrm{CO}_{2}$ corrosion. EIS studies on the inhibition efficiency of benzimidazole," Electrochimica Acta, vol. 48, no. 7, pp. 845-854, 2003.

[43] J. Serra, P. González, S. Liste et al., "FTIR and XPS studies of bioactive silica based glasses," Journal of Non-Crystalline Solids, vol. 332, no. 1-3, pp. 20-27, 2003.

[44] N. Moussaif, C. Pagnoulle, J. Riga, and R. Jérôme, "XPS analysis of the PC/PVDF interface modified by PMMA. Location of the PMMA at the interface," Polymer, vol. 41, no. 9, pp. 3391-3394, 2000.

[45] S.-M. Choi, W.-K. Yang, Y.-W. Yoo, and W.-K. Lee, "Effect of surface modification on the in vitro calcium phosphate growth on the surface of poly(methyl methacrylate) and bioactivity," Colloids and Surfaces B: Biointerfaces, vol. 76, no. 1, pp. 326-333, 2010.

[46] S. L. Iconaru, F. Ungureanu, A. Costescu, M. Costache, A. Dinischiotu, and D. Predoi, "Characterization of sucrose thin films for biomedical applications," Journal of Nanomaterials, vol. 2011, Article ID 291512, 6 pages, 2011.

[47] P. Prieto, V. Nistor, K. Nouneh, M. Oyama, M. Abd-Lefdil, and R. Díaz, "XPS study of silver, nickel and bimetallic silver-nickel nanoparticles prepared by seed-mediated growth," Applied Surface Science, vol. 258, no. 22, pp. 8807-8813, 2012.

[48] L. Chen, Y. Xia, X. Huang, X. Liang, J. Yin, and Z. Liu, "Influence of substrate temperature on the molecular structure of PMMA films deposited by pulsed laser deposition," Journal of Physics D: Applied Physics, vol. 40, no. 12, pp. 3649-3653, 2007.

[49] Y. Ma, X. Cao, X. Feng, and H. Zou, "Fabrication of superhydrophobic film from PMMA with intrinsic water contact angle below 90'," Polymer, vol. 48, no. 26, pp. 7455-7460, 2007.

[50] D. Y. Zemlyanov, E. R. Savinova, A. Scheybal, K. Doblhofer, and R. Schlögl, "XPS observation of OH groups incorporated in an Ag(111) electrode," Surface Science, vol. 418, no. 2, pp. 441-456, 1998.

[51] E. R. Savinova, D. Zemlyanov, B. Pettinger, A. Scheybal, R. Schlögl, and K. Doblhofer, "On the mechanism of Ag(111) submonolayer oxidation: a combined electrochemical, in situ SERS and ex situ XPS study," Electrochimica Acta, vol. 46, no. 2-3, pp. 175-183, 2000.
[52] T. Kawabe, S. Shimomura, T. Karasuda, K. Tabata, E. Suzuki, and Y. Yamaguchi, "Photoemission study of dissociatively adsorbed methane on a pre-oxidized $\mathrm{SnO}_{2}$ thin film," Surface Science, vol. 448, no. 2, pp. 101-107, 2000.

[53] J. L. Xu and K. A. Khor, "Chemical analysis of silica doped hydroxyapatite biomaterials consolidated by a spark plasma sintering method," Journal of Inorganic Biochemistry, vol. 101, no. 2, pp. 187-195, 2007.

[54] M. K. Jeon and M. Kang, "Synthesis and characterization of indium-tin-oxide particles prepared using sol-gel and solvothermal methods and their conductivities after fixation on polyethyleneterephthalate films," Materials Letters, vol. 62, no. 4-5, pp. 676-682, 2008.

[55] K. J. Carroll, J. U. Reveles, M. D. Shultz, S. N. Khanna, and E. E. Carpenter, "Preparation of elemental $\mathrm{Cu}$ and $\mathrm{Ni}$ nanoparticles by the polyol method: an experimental and theoretical approach," Journal of Physical Chemistry C, vol. 115, no. 6, pp. 2656-2664, 2011.

[56] X. Gao, S. R. Bare, J. L. G. Fierro, M. A. Banares, and I. E. Wachs, "Preparation and in-situ spectroscopic characterization of molecularly dispersed titanium oxide on silica," Journal of Physical Chemistry B, vol. 102, no. 29, pp. 5653-5666, 1998.

[57] A. Mekki, D. Holland, K. Ziq, and C. F. McConville, "XPS and magnetization studies of cobalt sodium silicate glasses," Journal of Non-Crystalline Solids, vol. 220, no. 2-3, pp. 267-279, 1997.

[58] A. Babapour, O. Akhavan, R. Azimirad, and A. Z. Moshfegh, "Physical characteristics of heat-treated nano-silvers dispersed in sol-gel silica matrix," Nanotechnology, vol. 17, no. 3, pp. 763771, 2006.

[59] A. Boyd, M. Akay, and B. J. Meenan, "Influence of target surface degradation on the properties of r.f. magnetron-sputtered calcium phosphate coatings," Surface and Interface Analysis, vol. 35, no. 2, pp. 188-198, 2003.

[60] S. Kačiulis, G. Mattogno, L. Pandolfi, M. Cavalli, G. Gnappi, and A. Montenero, "XPS study of apatite-based coatings prepared by sol-gel technique," Applied Surface Science, vol. 151, no. 1, pp. 1-5, 1999.

[61] T. F. Stoica, C. Morosanu, A. Slav et al., "Hydroxyapatite films obtained by sol-gel and sputtering," Thin Solid Films, vol. 516, no. 22, pp. 8112-8116, 2008.

[62] E. Sumesh, M. S. Bootharaju, and T. Pradeep, "A practical silver nanoparticle-based adsorbent for the removal of $\mathrm{Hg}^{2+}$ from water," Journal of Hazardous Materials, vol. 189, no. 1-2, pp. 450457, 2011.

[63] Y. Lai, H. Zhuang, K. Xie et al., "Fabrication of uniform $\mathrm{Ag} / \mathrm{TiO}{ }_{2}$ nanotube array structures with enhanced photoelectrochemical performance," New Journal of Chemistry, vol. 34, no. 7, pp. 13351340, 2010.

[64] J. S. Hammond, S. W. Gaarenstroom, and N. Winograd, "X-ray photoelectron spectroscopic studies of cadmium- and silveroxygen surfaces," Analytical Chemistry, vol. 47, no. 13, pp. 21932199, 1975.

[65] O. Akhavan, "Lasting antibacterial activities of $\mathrm{Ag}-\mathrm{TiO}_{2} / \mathrm{Ag} / \mathrm{a}-$ $\mathrm{TiO}_{2}$ nanocomposite thin film photocatalysts under solar light irradiation," Journal of Colloid and Interface Science, vol. 336, no. 1, pp. 117-124, 2009.

[66] A. Groza, "Review of the processes identified during the polymerization of organic and organosilicon liquid films in atmospheric pressure air corona discharges," Romanian Reports in Physics, vol. 64, no. 4, pp. 1227-1242, 2012.

[67] S. L. Iconaru, P. Chapon, P. Le Coustumer, and D. Predoi, "Antimicrobial activity of thin solid films of silver doped 
hydroxyapatite prepared by sol-gel method," The Scientific World Journal, vol. 2014, Article ID 165351, 8 pages, 2014.

[68] R. Valledor, J. Pisonero, N. Bordel et al., "Direct chemical indepth profile analysis and thickness quantification of nanometer multilayers using pulsed-rf-GD-TOFMS," Analytical and Bioanalytical Chemistry, vol. 396, no. 8, pp. 2881-2887, 2010.

[69] M. Jelinek, T. Kocourek, J. Remsa et al., "Antibacterial, cytotoxicity and physical properties of laser-silver doped hydroxyapatite layers," Materials Science and Engineering: C, vol. 33, no. 3, pp. 1242-1246, 2013.

[70] J. Kriengkauykiat, J. I. Ito, and S. S. Dadwal, "Epidemiology and treatment approaches in management of invasive fungal infections," Clinical Epidemiology, vol. 3, no. 1, pp. 175-191, 2011.

[71] F. Chapeland-Leclerc, C. Hennequin, N. Papon et al., "Acquisition of flucytosine, azole, and caspofungin resistance in Candida glabrata bloodstream isolates serially obtained from a hematopoietic stem cell transplant recipient," Antimicrobial Agents and Chemotherapy, vol. 54, no. 3, pp. 1360-1362, 2010.

[72] V. Lazăr and M. C. Chifiriuc, "Medical significance and new therapeutical strategies for biofilm associated infections," Roumanian Archives of Microbiology and Immunology, vol. 69, no. 3, pp. 125-138, 2010.

[73] M. M. Harriott and M. C. Noverr, "Importance of Candidabacterial polymicrobial biofilms in disease," Trends in Microbiology, vol. 19, no. 11, pp. 557-563, 2011.

[74] V. Lazar, Microbial Adherence, Roumanian Academy Publishing House, 2003.

[75] J. Chandra, D. M. Kuhn, P. K. Mukherjee, L. L. Hoyer, T. McCormick, and M. A. Ghannoum, "Biofilm formation by the fungal pathogen Candida albicans: development, architecture, and drug resistance," Journal of Bacteriology, vol. 183, no. 18, pp. 5385-5394, 2001.

[76] E. M. Kojic and R. O. Darouiche, "Candida infections of medical devices," Clinical Microbiology Reviews, vol. 17, no. 2, pp. 255267, 2004.

[77] J. A. Crump and P. J. Collignon, "Intravascular catheter-associated infections," European Journal of Clinical Microbiology and Infectious Diseases, vol. 19, no. 1, pp. 1-8, 2000.

[78] R. M. Dominic, S. Shenoy, and S. Baliga, "Candida biofilms in medical devices: evolving trends," Kathmandu University Medical Journal, vol. 5, no. 19, pp. 431-436, 2007.

[79] A. Dongari-Bagtzoglou, H. Kashleva, P. Dwivedi, P. Diaz, and J. Vasilakos, "Characterization of mucosal Candida albicans biofilms," PLoS ONE, vol. 4, no. 11, Article ID e7967, 2009.

[80] M. M. Harriott, E. A. Lilly, T. E. Rodriguez, P. L. Fidel Jr., and M. C. Noverr, "Candida albicans forms biofilms on the vaginal mucosa," Microbiology, vol. 156, no. 12, pp. 3635-3644, 2010.

[81] G. Ramage, K. VandeWalle, B. L. Wickes, and J. L. López-Ribot, "Characteristics of biofilm formation by Candida albicans," Revista Iberoamericana de Micologia, vol. 18, no. 4, pp. 163-170, 2001.

[82] G. S. Baillie and L. J. Douglas, "Matrix polymers of Candida biofilms and their possible role in biofilm resistance to antifungal agents," Journal of Antimicrobial Chemotherapy, vol. 46, no. 3, pp. 397-403, 2000.

[83] S. Luo, C. Skerka, O. Kurzai, and P. F. Zipfel, "Complement and innate immune evasion strategies of the human pathogenic fungus Candida albicans," Molecular Immunology, vol. 56, no. 3, pp. 161-169, 2013.

[84] A. Taglietti, C. R. Arciola, A. D’Agostino et al., "Antibiofilm activity of a monolayer of silver nanoparticles anchored to an amino-silanized glass surface," Biomaterials, vol. 35, no. 6, pp. 1779-1788, 2014.

[85] C. S. Ciobanu, S. L. Iconaru, M. C. Chifiriuc, A. Costescu, P. Le Coustumer, and D. Predoi, "Synthesis and antimicrobial activity of silver-doped hydroxyapatite nanoparticles," BioMed Research International, vol. 2013, Article ID 916218, 10 pages, 2013.

[86] A. Costescu, C. S. Ciobanu, S. L. Iconaru et al., "Fabrication, characterization, and antimicrobial activity, evaluation of low silver concentrations in silver-doped hydroxyapatite nanoparticles," Journal of Nanomaterials, vol. 2013, Article ID 194854, 9 pages, 2013.

[87] D. Campoccia, L. Montanaro, and C. R. Arciola, "A review of the clinical implications of anti-infective biomaterials and infection-resistant surfaces," Biomaterials, vol. 34, no. 33, pp. 8018-8029, 2013.

[88] D. Campoccia, L. Montanaro, and C. R. Arciola, "A review of the biomaterials technologies for infection-resistant surfaces," Biomaterials, vol. 34, no. 34, pp. 8533-8554, 2013.

[89] J. Pemán, R. Zaragoza, G. Quindós et al., "Clinical factors associated with a Candida albicans germ tube antibody positive test in intensive care unit patients," BMC Infectious Diseases, vol. 11, no. 1, article 60, 2011.

[90] P. Viale, "Candida colonization and candiduria in critically ill patients in the intensive care unit," Drugs, vol. 69, supplement 1, pp. 51-57, 2009.

[91] R. B. Shinde, J. S. Raut, and M. S. Karuppayil, "Biofilm formation by Candida albicans on various prosthetic materials and its fluconazole sensitivity: a kinetic study," Mycoscience, vol. 53, no. 3, pp. 220-226, 2012.

[92] M. El-Azizi and N. Khardori, "Factors influencing adherence of Candida spp. to host tissues and plastic surfaces," Indian Journal of Experimental Biology, vol. 37, no. 10, pp. 941-951, 1999.

[93] J. Raut, V. Rathod, and S. M. Karuppayil, "Cell surface hydrophobicity and adhesion: a study on fifty clinical isolates of Candida albicans," Japanese Journal of Medical Mycology, vol. 51, no. 3, pp. 131-136, 2010.

[94] M. A. Pfaller, D. J. Diekema, R. N. Jones et al., "International surveillance of bloodstream infections due to Candida species: frequency of occurrence and in vitro susceptibilities to fluconazole, ravuconazole, and voriconazole of isolates collected from 1997 through 1999 in the SENTRY antimicrobial surveillance program," Journal of Clinical Microbiology, vol. 39, no. 9, pp. 3254-3259, 2001. 

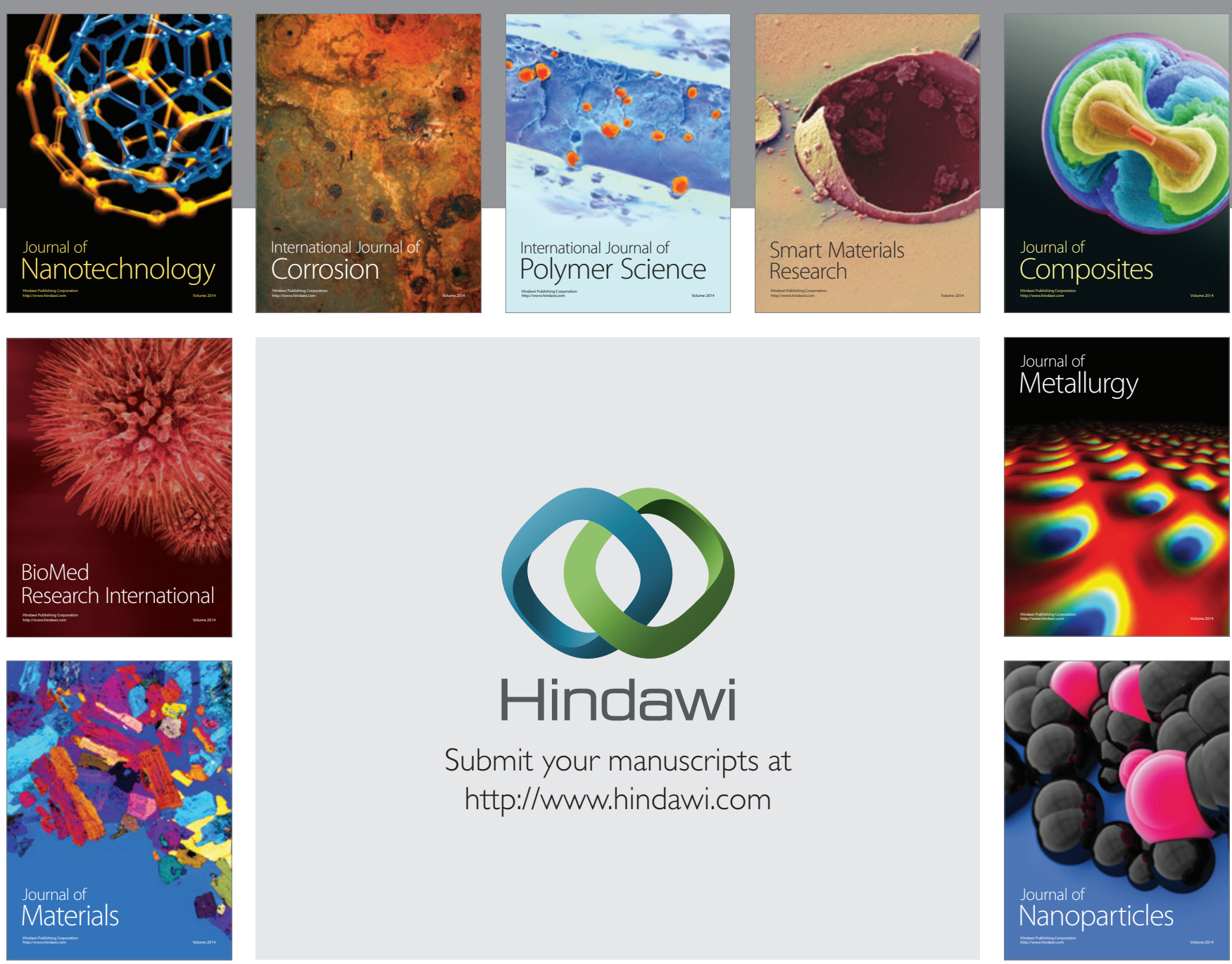

Submit your manuscripts at http://www.hindawi.com
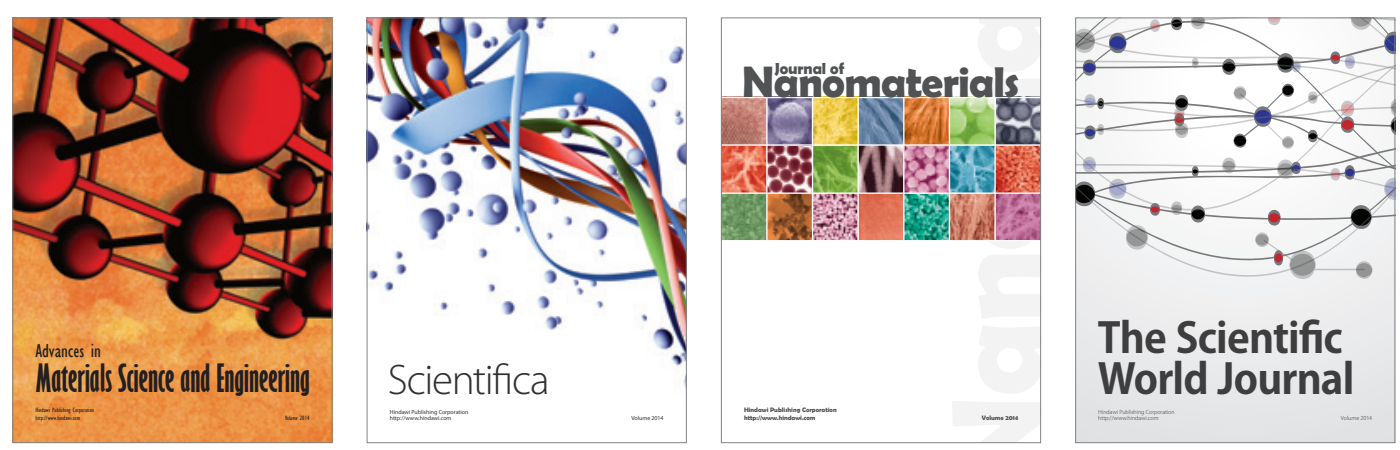

\section{The Scientific World Journal}
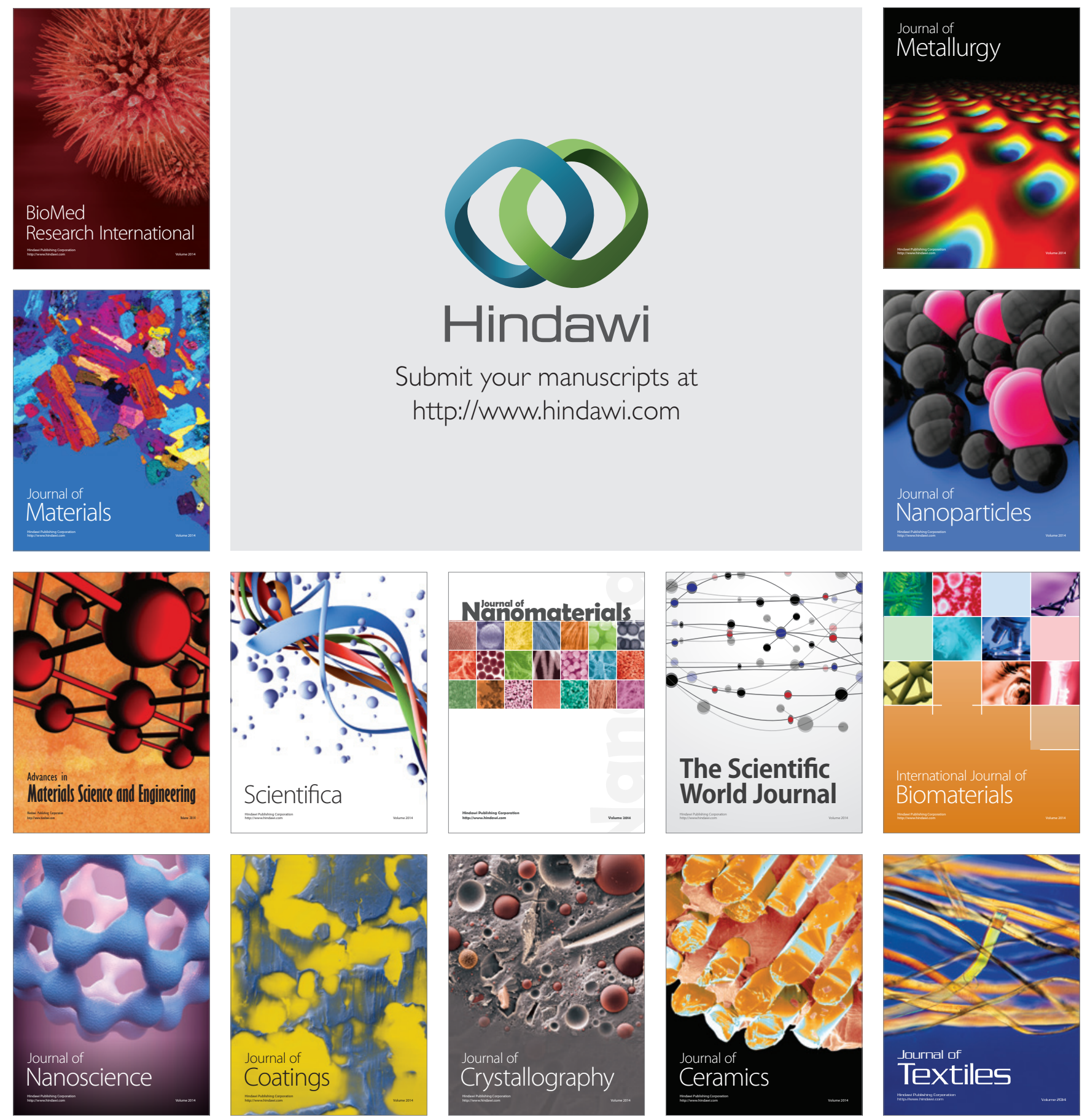